\title{
PROPOSTA DE COLETA SELETIVA PARA PONTOS DE ÔNIBUS NAS PROXIMIDADES DO CAMPUS II DE PRESIDENTE PRUDENTE - SP
}

\section{SELECTED COLLECTION PROPOSAL FOR BUS POINTS NEAR THE CAMPUS II OF PRESIDENTE PRUDENTE - SP}

\author{
Bruna Oliveira Silva', Hugo Ichikawa de Campos'; Rafael Henrique Garcez \\ Nicolau'; Isabela Marega Rigolin Fuzeto'; \\ 1 Universidade do Oeste Paulista - UNOESTE, Curso de Engenharia Ambiental e \\ Sanitária, Pres. Prudente, SP \\ E-mail: brunaoliveiraff@hotmail.com
}

RESUMO - Resíduos sólidos descartados inadequadamente têm se tornado um problema cada vez maior, proporcional ao crescimento demográfico. Há um quadro bastante preocupante no que diz respeito ao descarte de resíduos sólidos no país. Resíduos mal descartados muitas vezes acabam se transformando em problemas ambientais com gerenciamento oneroso e complexo. Sendo assim, o presente projeto teve como objetivo quantificar os resíduos sólidos recicláveis descartados nas proximidades dos pontos de ônibus do Campus II da Unoeste, em Presidente Prudente - SP, e assim propor uma coleta e descarte ambientalmente adequado. $O$ trabalho foi feito em duas etapas, a primeira sendo a coleta dos resíduos nos pontos selecionados em horários específicos e a segunda sendo a separação e pesagem dos mesmos, sintetizando os resultados em tabelas a fim de se fazer o delineamento estatístico. O peso total dos resíduos coletados nos períodos manhã, tarde e noite foi de $24,9 \mathrm{~kg}$. Segundo a projeção estatística, em um ano um total de 968,4 $\mathrm{Kg}$ de resíduos seriam descartados inadequadamente nas vias urbanas, necessitando assim de pontos de coletas estratégicos, bem como a educação ambiental da população como um todo.

Palavras-chave: Resíduos urbanos, coleta seletiva, descarte final.

ABSTRACT - Improperly discarded solid waste has become a growing problem, proportional to population growth. There is a very worrying picture regarding the disposal of solid waste in the country. Poorly discarded waste often turns into environmental problems with costly and complex management. Therefore, the present project had the objective of quantifying the recyclable solid waste discarded in the vicinity of the Unoeste Campus II bus stops, in Presidente Prudente - SP, and thus propose an environmentally adequate collection and disposal. The work was done in two stages, the first being the collection of the residues at the selected points at specific times and the second being the separation and weighing of the same, synthesizing the results into tables in order to do the statistical design. The total weight of the collected residues in the morning, afternoon and night periods was $24.9 \mathrm{~kg}$. According to the statistical projection, in one year a total of $968.4 \mathrm{~kg}$ of waste would be inappropriately discarded in urban roads, thus requiring strategic collection points, as well as the environmental education of the population as a whole.

Keywords: Urban waste, selective collection, final disposal. 


\section{INTRODUÇÃO}

O grande crescimento demográfico, 0 ininterrupto desenvolvimento da malha urbana e as necessidades de consumo cada vez maiores e muitas vezes triviais pedem uma demanda cada vez maior de exploração de recursos naturais, afim de suprir a sociedade com bens duráveis e não duráveis, o que por sua vez representa maiores impactos na natureza.

Há um interesse geral em assuntos associados ao desenvolvimento sustentável e medidas mitigadoras, isto é, medidas que visam minimizar os impactos causados pelo homem, sempre considerando o contexto social e as políticas públicas envolvidas (TAKENAKA, 2012).

A este respeito, o Brasil sendo um país em constante desenvolvimento também tem de lidar com tais desafios, uma vez que as indústrias se utilizam de novos e eficientes métodos e tecnologias para otimizar suas produções e qualidades de serviço, o que por sua vez gera um maior consumo, originando ainda mais resíduos sólidos urbanos. No ano de 2012, levantamentos estatísticos mostraram que foram coletados em média 183 mil toneladas de resíduos urbanos diários no Brasil, e que, embora a quantidade fosse alarmante, a grande preocupação era a destinação final de tais resíduos, que na maioria das vezes era descartado inadequadamente (RIBEIRO, 2013).

Os resíduos se transformaram em graves problemas urbanos e ambientais com um gerenciamento, na maioria das vezes, oneroso e complexo. A escassez de áreas de deposição de resíduos causadas pela ocupação e valorização de áreas urbanas, os altos custos sociais no gerenciamento de resíduos, problemas de saneamento público e contaminação ambiental são alguns destes problemas (JOHN, 2000).

Assim sendo, utilizando as informações coletadas na síntese de literatura, é proposto um estudo de resíduos sólidos recicláveis descartados inadequadamente próximo aos pontos de ônibus nas proximidades do Campus II da Unoeste de Presidente Prudente - SP.

O objetivo deste trabalho é obter, por meio de dados estatísticos, a quantidade em quilogramas de resíduos sólidos descartados inapropriadamente próximos a pontos de ônibus nas proximidades do Campus II da Unoeste de Presidente Prudente - SP, que deixariam de ir para os sistemas de esgotos e drenagem urbana se houvesse coleta seletiva em tais localidades, considerando seus tipos e classificações, bem como uma forma barata e eficiente de coleta.

\section{METODOLOGIA}

O seguinte trabalho consiste no diagnóstico dos resíduos depositados nos pontos de ônibus ao redor da Unoeste, sendo realizado através de coleta feita no mês de março, em período de aulas e outra no mês de julho, período de férias da instituição. Possibilitando o conhecimento da situação atual dos pontos de ônibus em relação à quantidade de Resíduos que cada um suporta e a forma de disposição final.

A realização do trabalho foi subdividida nas seguintes etapas:

\subsection{Coletas de Dados}

Em um primeiro momento, foram selecionados estrategicamente os pontos de ônibus nas proximidades do Campus II de Presidente Prudente como mostra a figura 1 que possuem maiores fluxos diário de pessoas. Em seguida, foram feitas demarcações em cada um dos pontos de ônibus selecionados, que delimitou um raio de 10 a 15 metros ao redor de cada ponto.

Figura 1. Pontos selecionados para coleta.

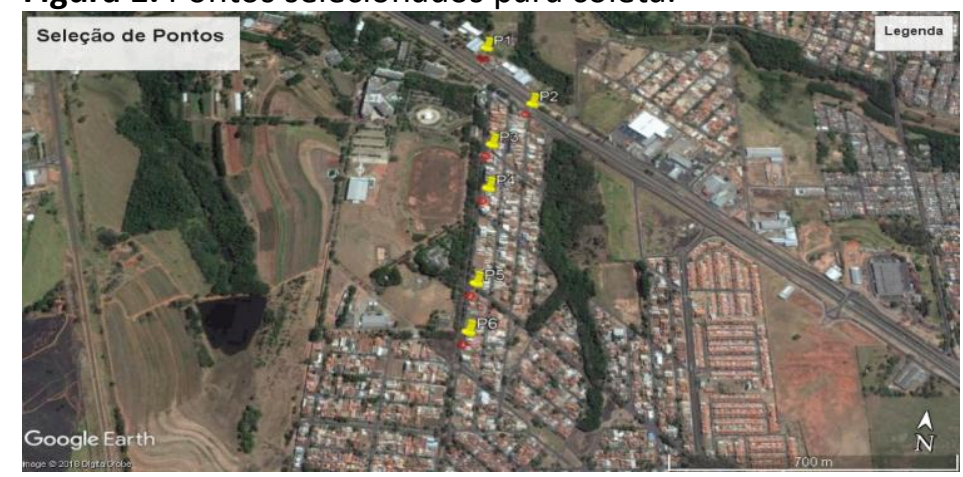

Fonte: Autores (2018)

\subsection{Caracterização dos Resíduos}

Em seguida, foi feita a coleta dos resíduos sólidos descartados dentro do raio delimitado ao final de cada dia, durante sete dias subsequentes. Os resíduos coletados passaram por uma fase de separação de acordo com suas respectivas categorias, seguindo o método de quarteamento da NBR 1007/197 ABNT.

Para facilitar o estudo os resíduos foram subdivididos em: Resíduos Recicláveis: papel, plástico, vidro, metal; Resíduos Orgânicos: restos de alimentos; Rejeitos: materiais sujos e 
provenientes do banheiro; Outros Resíduos: todos os outros resíduos que não se encaixavam em recicláveis, orgânicos e rejeitos.

Figura 2: Resíduos da coleta

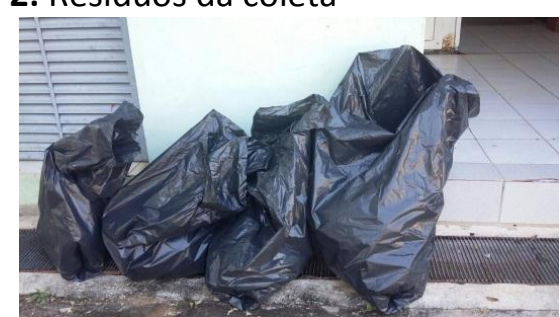

Fonte: Autores (2018)

Figura 3: Resíduos da coleta

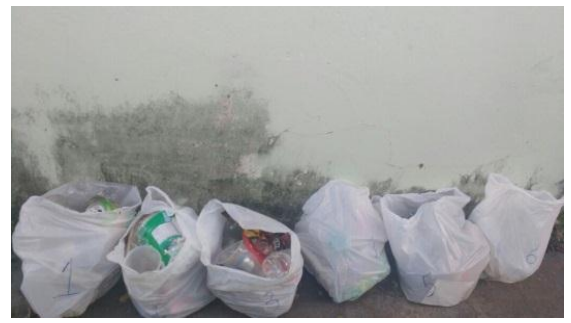

Fonte: Autores (2018)

\subsection{Pesagem dos Resíduos}

Depois de separados, os resíduos foram pesados de modo a se obter uma média estatística sobre a proporção de cada tipo de resíduo descartado em cada um dos dias de avaliação.

Figura 4. Balança utilizada na pesagem.

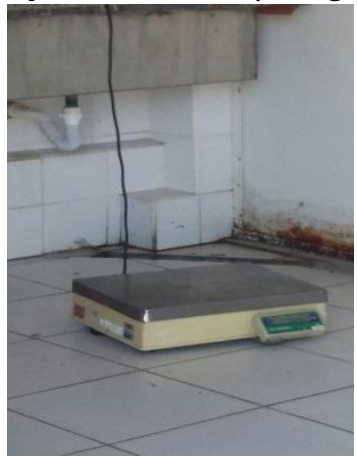

Fonte: Autores (2018)

Figura 5: Balança em funcionamento.

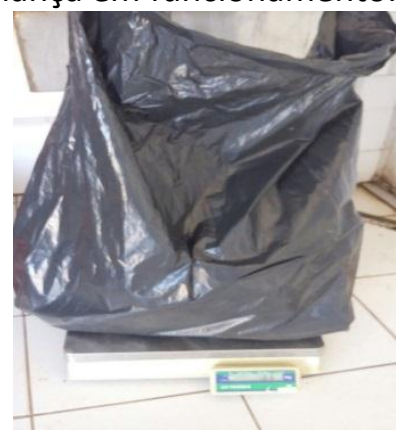

Fonte: Autores (2018)

\subsection{Analise dos Resultados}

Com os resultados das pesagens pode-se analisar os motivos de alguns pontos terem mais resíduos do que os outros.

\section{RESULTADOS}

A primeira coleta foi realizada no mês de março, logo após o período de volta as aulas, com o intuito de aproveitar o grande fluxo de alunos nos pontos de ônibus no Campus 2. A coleta foi realizada nos períodos da manhã, tarde e noite após o horário de aula no final de cada período, onde a cada semana do mês era intercalado os períodos de coleta, obtendo os resultados da tabela 1. Na tabela 2, é mostrado o resultado das coletas em período de férias, onde o fluxo de pessoas que utilizam os determinados pontos era visivelmente menor. Foi utilizado o método de amostragem para chegarmos aos valores encontrados na tabela 3 , onde foram calculados estatisticamente dados semanais, mensais e anual, considerado os períodos letivos e períodos de férias.

Tabela 1: Peso dos resíduos em época de aula.

Fonte: Autores (2018)

\begin{tabular}{|l|c|}
\hline PERÍODO & PESO (KL) \\
\hline MANHÃ & 9,5 \\
\hline TARDE & 6,1 \\
\hline NOITE & 9,4 \\
\hline
\end{tabular}

Tabela 2. Peso dos resíduos em época de férias.

\begin{tabular}{|l|c|}
\hline PERÍODO & PESO (KL) \\
\hline MANHÃ & 2,8 \\
\hline TARDE & 1,2 \\
\hline NOITE & 2 \\
\hline
\end{tabular}

Fonte: Autores (2018) 
Tabela 3: Projeção estatística.

\begin{tabular}{|c|c|c|}
\hline & $\begin{array}{c}\text { Períodos de } \\
\text { Aula (Peso } \\
\mathrm{kg} \text { ) }\end{array}$ & $\begin{array}{c}\text { Período de } \\
\text { Férias } \\
\text { (Peso kg) }\end{array}$ \\
\hline SEMANAL & 24,9 & 6 \\
\hline MENSAL & 99,6 & 24 \\
\hline $\begin{array}{c}\text { PERÍODO } \\
\text { LETIVO/PERÍDO } \\
\text { DE FÉRIAS }\end{array}$ & 896,4 & 72 \\
\hline TOTAL & & 968,4 \\
\hline
\end{tabular}

Fonte: Autores (2018)

\section{DISCUSSÃO}

Foi possível avaliar através das projeções feitas que a quantidade de resíduos descartados anualmente nas proximidades de pontos de ônibus do Campus II da Unoeste é de cerca de $968,4 \mathrm{~kg}$, uma quantidade considerável no cenário urbano de Presidente Prudente.

Tal descarte inadequado dos resíduos pode ser o reflexo da defasagem da educação ambiental, tanto no âmbito universitário com da população no geral.

Faz-se necessário medidas de educação ambiental e medidas de coleta e descarte que sejam ambientalmente compatíveis, e a realização de auditorias para acompanhar a eficácia das medidas adotadas.

\section{CONSIDERAÇÕES FINAIS}

Espera-se, com a obtenção dos dados estatísticos e diagnóstico sobre os resíduos sólidos um a implementação de medidas ambientais adequadas. Propõe-se a implantação de coleta seletiva nos pontos de ônibus estudados bem como informativos locais que estimulem a consciência ambiental. Com a coleta seletiva ativa em pontos de ônibus, torna-se mais fácil o recolhimento dos resíduos pela Cooperativa de Catadores, que por sua vez darão a destinação adequada. Propõe-se também a educação ambiental da população e dos universitários através de projetos de extensão e cursos de treinamento.

\section{REFERÊNCIAS}

BARROS, R. T. V. et al. Manual de Saneamento e Proteção Ambiental Para os Municípios. Escola de Engenharia da UFMG, Belo Horizonte - MG,
2003, 221p. Disponível em: http://rdigital.univille.rctsc.br/index.php/RSA/arti cle/viewfile/91/146\%3E.

BRASIL. Resolução CONAMA no 001 de 1986. Disponível em:

<http://www.mma.gov.br/port/conama/res/res8 6/res0186.html>

FONSECA. Iniciação do Estudo de Resíduos Sólidos e da Limpeza Urbana: A União. 1999.122p.

JOHN, V. M; ANGULO, S.C; AGOPYAN, V. Sobre a necessidade de metodologia de pesquisa $e$ desenvolvimento para reciclagem. PCC Departamento Engenharia de Construção Civil da Escola Politécnica. EP USP. Disponível em: $<$ http://www.ichs.ufop.br/cadernosdehistoria/do wnload/CadernosDeHistoria-04->

JUNIOR, E. F. DE O.; FREIRE, R. S. Os Impactos Ambientais Decorrentes da Produção de Resíduos Sólidos Urbanos e Seus Riscos à Saúde Humana. Revista Eletrônica da Faculdade José Augusto Vieira. Ano $\mathrm{VI}-\mathrm{n}^{\circ}$ 8, Setembro de 2013 - ISSN - 1983-1285.

MOTA, J.C.; ALMEIDA, M. M. DE; ALENCAR, V. C. DE; CURI, W. F. Características e Impactos Ambientais Causados Pelos Resíduos Sólidos: Uma Visão Conceitual. I Congresso Internacional de Meio Ambiente Subterrâneo.

RIBEIRO, S. G. Gerenciamento de Resíduos Sólidos Urbanos No Município de Lagarto/SE. Faculdade José Augusto Vieira. Lagarto/SE, 2013.

TAKENAKA, E.M.M. Políticas Públicas de Gerenciamento Integrado de Resíduos Sólidos Urbanos no Município de Presidente PrudenteSP. Presidente Prudente: UNESP,2008. 